\title{
SUGGESTION OF INITIATING THREATS AND BOUNDING GROUPS For NuClear PoWer Plant Cyber-Risk ASSESSMENT
}

\author{
Sang Min Han \& Poong Hyun Seong
}
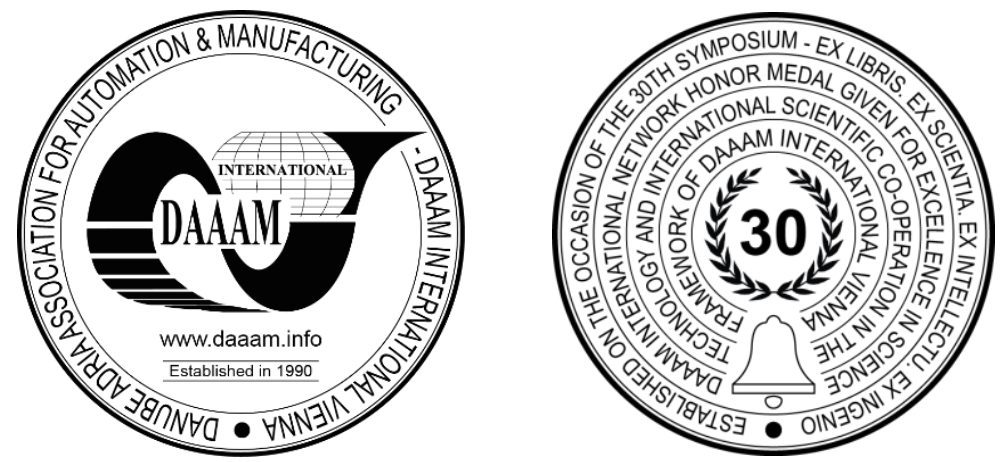

This Publication has to be referred as: Han, S[ang] M[in] \& Seong, P[oong] H[yun] (2019). Suggestion of Initiating Threats and Bounding Groups for Nuclear Power Plant Cyber-Risk Assessment, Proceedings of the 30th DAAAM International Symposium, pp.0853-0859, B. Katalinic (Ed.), Published by DAAAM International, ISBN 978-3-90273422-8, ISSN 1726-9679, Vienna, Austria

DOI: $10.2507 / 30$ th.daaam.proceedings.118

\begin{abstract}
As one of the largest safety-critical infrastructure, nuclear power plants (NPPs), adopt digital technologies, cyber security has become a natural issue. Nonetheless, compared to other complex systems, the development of a cyber-risk assessment method for NPPs is in its infancy. As a start of developing cyber-risk assessment methodology, initiating threats and their bounding were suggested through incident history analysis. Major 4 scenarios were developed and their bounding groups were suggested by their nature of attacks. The study is meaningful in that it presents all initiating threats and their bounding groups based on the historical incidents, and also it could be further applied to describe scenarios and models of NPP cyber-risk assessments.
\end{abstract}

Keywords: Cyber-security; Risk assessment; Historical incident analysis; Initiating threats; Bounding groups;

\section{Introduction \\ 1.1. Background}

As safety-critical infrastructures have become complex and increasingly adopted digital technologies and automation, cyber security became a natural issue. Nuclear power plants (NPPs), one of the safety-critical infrastructures, are generally thought to be secure from cyber-attacks, as the control/monitoring network and business network in a NPP are separate from the external network. However, consecutive incidents at nuclear facilities, such as the Hatch NPP incident in 2008, the Natanz nuclear facility incident in 2010, the Monju NPP incident in 2014, and the Gundremmingen NPP incident in 2016 have revealed the necessity of cyber security management for NPPs. Nonetheless, compared to other safety-critical infrastructure elements, such as process plants and chemical plants, the development of a cyber-risk assessment method for NPPs is in its infancy. 
To enhance the cybersecurity of a system, CSF (Cyber Security Framework) ver. 1.1 was suggested by NIST (National Institute of Standards and Technology) at the 2018 NIST Cybersecurity Risk Management Conference [1]. CSF focuses on five functions to enhance cyber security: 1) identify, 2 protect, 3) detect, 4) respond, and 5) recover. The nuclear industry is in its very first phase of implementing CSF functions at NPPs. The identify function, which implies the development of organizational understanding to manage cyber security risks to systems, assets, data, and capabilities, includes the development of a cyber-risk assessment method.

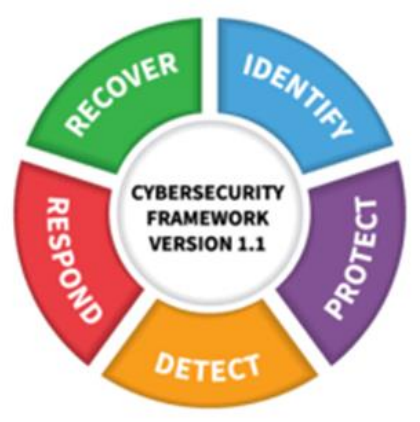

Fig. 1. CSF and main functions

Several methods have been developed for assessing the levels of cyber-risk at NPPs [2][3][4][5][6]; however, risk assessment methods so far have been focused on engineering evaluation and expert judgement when developing cyberattack scenarios. In addition, there was no statistical list of general cyber threats for NPP. In order to consider the applicability to conventional risk analysis method and subjectivity of the developed scenario, the 'initiating threats' has been suggested in the paper. The next section describes the concept and the necessity of the initiating threats.

\subsection{Initiating events and initiating threats}

Initiating events during a probabilistic safety assessment determine the points of departure of accident sequences that potentially lead to core damage. A missing initiating event in a PSA means that the core damage frequency will be underestimated, and a larger list of initiating events than necessary (for example, due to inappropriate grouping) would result in a waste of resources due to the analyses of additional unnecessary accident sequences. Therefore, the appropriate selections of initiating events and their bounding groups are required to assess risk. In the same vein, initiating threats also should have a tidy list for the appropriate assessment of the risks at NPPs. After setting up the list of initiating threats, it is appropriate to consider bounding groups to establish a response strategy to handle initiating threats efficiently. The grouping of initiating events in PSA shall be created in such a way that all events in the group impose essentially the same success criteria and result in the same core damage state. From the perspective of cyber security, the grouping of initiating threats by their purpose is also desirable, as the response strategies depend on the nature of the security infringement, i.e., confidentiality, integrity, and availability (CIA). Therefore, in this paper, initiating threats and their bounding groups will be proposed as a start to the development of a cyber-risk assessment.

\subsection{Threat modelling}

Endeavours in the information technology (IT) field have established a solid foundation of the modelling cyber threats from three different perspectives: 1) focusing on assets, 2) focusing on software, and 3) focusing on attackers [7]. Focusing on assets is the most common method used to analyse threats. However, no one would be concerned if an attacked asset is not valuable, even if the attack succeeded. An analysis of an attack on assets may be useful to experts who can systematically classify the entire set of assets of a system; however, in general such an analysis often only focuses on certain critical assets. In cases when the analysis focuses on software, the analysis could be helpful to software developers who understand the overall software architecture. However, this analysis is also infeasible for safety-critical industries, including the nuclear industry, in which the source code of the software would never be made available to the public. On the other hand, the 'focusing on attackers' method is helpful for understanding the possible practical threats to the system. Focusing on the attacker has advantages when analysing the purpose of an attack, as opposed to analysing 'how' and 'by what route the attack has been carried out. Safety-critical industries including the nuclear industry have comparably limited routes of attacks, and it is more important to determine which aspect of security has been infringed upon. Therefore in this study, we undertake threat modelling from the attacker perspective in an effort to identify and group initiating threats and their bounding groups at NPPs.

\section{Methods}

IAEA-TECDOC-719 suggests several methods to collect data pertaining to initiating events: 1) engineering evaluations or technical studies, 2) references to previous PSAs, 3) EPRI lists of initiating events, 4) logical classifications, 
5) a plant energy balance fault tree, 6) an analysis of the operation experience of the actual plant, 7) a failure mode and effect analysis, or 8) other methods [8]. Given that there are no former lists or analysis results for assessing NPP initiating threats, to determine threats and their bounding groups for NPPs, operational experience was chosen as the means by which to collect data about initiating threats in this paper. Operational experience includes operational experience reports (henceforth simply OER) from NPPs, department of homeland security (DHS), department of energy (DOE), Industrial control system-cyber emergency response team (ICS-CERT), nuclear threat initiative (NTI), and repository of industrial security incidents (RISI) database [9]-[31]. Total 164 reported incidents occurred from 1992 to 2016 were investigated. Among the reported incidents, 78 incidents caused by the secured development and operational environment (SDOE) were filtered out, as the nuclear industry is the only industry that interprets the incidents caused by SDOE and cyber security separately, among safety-critical industries. Distinguishable features of cyber security and SDOE are shown in the table 1 . Other 86 incidents were related to the cyber security issues, and 20 incidents were directly related to the nuclear industry.

\begin{tabular}{|c|c|c|}
\hline Definition & $\begin{array}{c}\text { Cyber Security } \\
\text { Measures and controls to protect CDAs against } \\
\text { the malicious act of an adversary, up to and } \\
\text { including the DBT }\end{array}$ & $\begin{array}{c}\text { Measures and controls taken to establish a } \\
\text { secure environment for development of the } \\
\text { digital safety system against undocumented, } \\
\text { unneeded and unwanted modifications and (2) } \\
\text { protective actions taken against a predictable } \\
\text { set of undesirable acts that could challenge the } \\
\text { integrity, reliability, or functionality of a digital } \\
\text { safety system during operations }\end{array}$ \\
\hline $\begin{array}{c}\text { Regulation } \\
\text { Suidelines or }\end{array}$ & $\begin{array}{c}\text { Regulatory Guide 1.152 } \\
\text { Cyber Security Programs for Nuclear Facilities }\end{array}$ & $\begin{array}{c}\text { Criteria for Use of Computers in Safety } \\
\text { Systems of Nuclear Power Plants }\end{array}$ \\
\hline Approaches & $\begin{array}{c}\text {-Cyber security program/plan establishment } \\
\text {-Application of technical/ operational/ } \\
\text { management control }\end{array}$ & $\begin{array}{c}\text {-Analysis, evaluation, V\&V, management of } \\
\text { software by its lifecycle phase } \\
\text {-Application of design characteristics for better } \\
\text { secure environment }\end{array}$ \\
\hline
\end{tabular}

Table 1. Cyber security vs. SDOE for digitalized instrumentation and control system [32]

Each of the chosen incidents was documented with descriptions based on the following five characteristics: 1) type of attacker, 2) intentionality, 3) access method, 4) access type, and 5) purpose of the attack. Characteristics 1 through 4 are for determining the initiating threat scenarios of attacks by the abovementioned 'focusing on attackers' strategy. The last characteristic, 'purpose of the attack', is for determining the type of infringement, which also can be thought of as a bounding group criterion of initiating threats, as mentioned in section 1.2. Stealing and leaking information and sniffing were classified as infringements of the confidentiality of a system; modifying and deleting information and the temporary disabling of functions were classified as infringements of the integrity of a system; and taking control and the disabling of a system, including denial of service (DoS) attacks, were classified as infringements of the availability of a system. Cyber-attack characteristics and their properties are shown in table 2.

\begin{tabular}{|c|c|}
\hline $\begin{array}{c}\text { Characteristics of } \\
\text { Initiating Cyber Threats }\end{array}$ & Properties \\
\hline \multirow{3}{*}{ Type of attacker } & (1) Outsider \\
\cline { 2 - 2 } & (2)Insider \\
\cline { 2 - 2 } & (3) Disgruntled or Corrupted (Formal) Employee \\
\cline { 2 - 2 } Intentionality & (4) Deliberately \\
\cline { 2 - 2 } & (5) Unintentionally \\
\cline { 2 - 2 } Access point & (6) Physical Access \\
\cline { 2 - 2 } & (7) Vulnerabilities \\
\hline \multirow{2}{*}{ Access type } & (8) Portable Media \\
\cline { 2 - 2 } & (9) Direct Access \\
\hline \multirow{2}{*}{ Purpose of attack } & (10) Remote Access \\
\cline { 2 - 2 } & (11) Infringement of Confidentiality \\
\cline { 2 - 2 } & (12) Infringement of Integrity \\
\hline
\end{tabular}

Table 2. Attack characteristics and their properties 


\section{Results}

In this study, 78 incidents among 164 incidents were revealed as SDOE issues, including inappropriate designs of network structures, malfunctions of a system, or cases of imperfect control logic implementation. The proportion of SDOE is high because, as noted earlier, other industries do not distinguish SDOE from cyber security. The following table shows the composition of the 164 incidents.

After filtering out 78 SDOE incidents, the remaining 86 incidents were analysed to determine the initiating threats. Five descriptive characteristics pertaining to the incidents, 'type of attacker', 'intentionality', 'access method', 'access type', and 'purpose of an attack' were utilized. The property sets of the initiating threat scenarios are shown in Table 3. All of the incidents were classified into the following four initiating threat scenarios.

\begin{tabular}{|c|c|}
\hline Initiating Cyber Threats & Property Set \\
\hline Threat 1 & 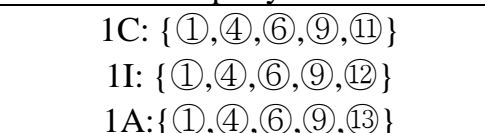 \\
\hline Threat 2 & $\begin{array}{l}2 \mathrm{C}:\{(1),(4),(7),(10),(11)\} \\
2 \mathrm{I}:\{(1),(4),(7),(10),(12)\} \\
2 \mathrm{~A}:\{1,,(4),(7),(10,(13)\}\end{array}$ \\
\hline Threat 3 & $\begin{array}{l}3 \text { 3C: }\{(1),(4),(8),(2),(5),(6),(9),(10,(11)\} \\
3 \mathrm{I}:\{(1),(4),(8),(2),(5),(6),(9),(1),(12)\} \\
3 \mathrm{~A}:\{(1),(4),(8),(2),(5),(6), 9,(10,(13\}\end{array}$ \\
\hline Threat 4 & $\begin{array}{l}\text { 4C: }\{(3),(4),(9),(11)\},\{(3),(4),(10,(11)\} \\
4 \mathrm{I}:\{(3),(4),(9),(12)\},\{(3),(4),(10),(12)\} \\
\text { 4A: }\{(3),(4),(9),(13)\},\{(3),(4),(10),(13)\}\end{array}$ \\
\hline
\end{tabular}

Table 3. Property set of each initiating threats

Initiating threat scenario 1 represents a situation in which an outside attacker physically and directly accesses a target to push malware into the target. Scenario 2 implies an outside attacker who has found a vulnerability of a target and accesses the target to push malware into the target. Scenario 3 is the most complicated but also the most common case, which includes both outsiders and insiders. An outsider deliberately or generally infects the insider's media, such as a laptop or USB device. The insider (including third parties and contractors) then unintentionally gives the outsider remote access by physically and directly connecting the media to the target during maintenance or update processes. Scenario 4 represents a disgruntled or corrupted employee or a formal employee who uses one's allowed authority. Alternatively, the authority has not yet been deleted and this attacker accesses the target directly or remotely. Proportions of each scenario with all incidents, power and utility industry, and nuclear industry are shown in Fig. 2, Fig. 3, and Fig. 4. In the case of the nuclear industry, the proportion of threats 3 and 4 was significantly higher than that of the whole industry, and threat 2 was lower than that of the whole industry. In other words, the nuclear power plant is an environment where it is difficult for an outsider attacker to infiltrate remotely, which is why the proportion of the scenario in which the insider attack is increased.

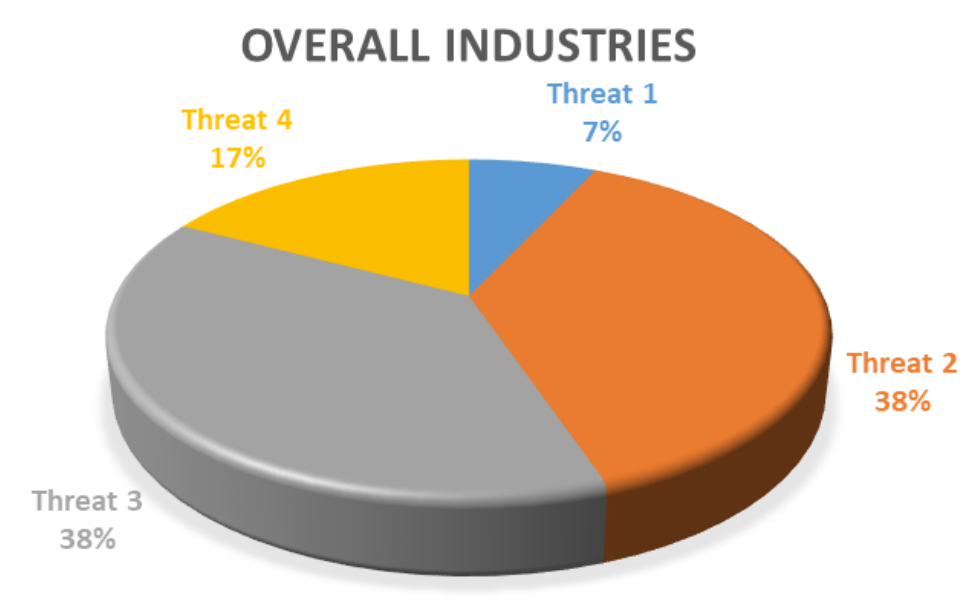

Fig. 2. Percentage of each threat for all industries 


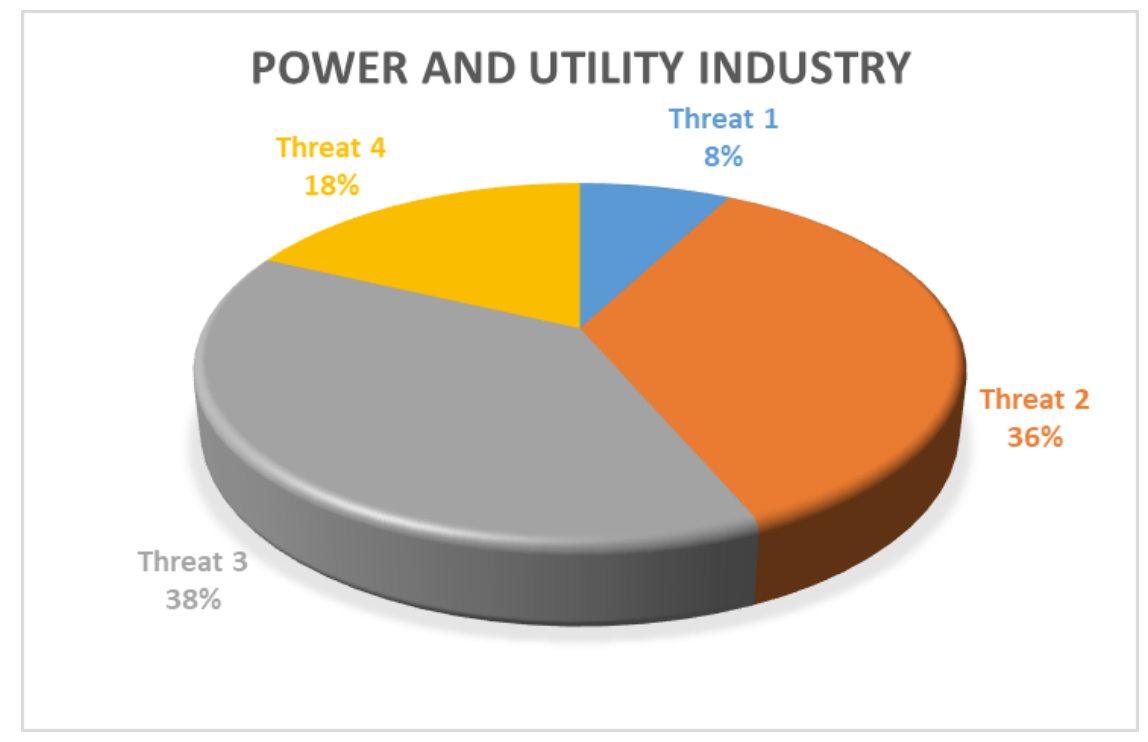

Fig. 3. Percentage of each threat for power and utility industry

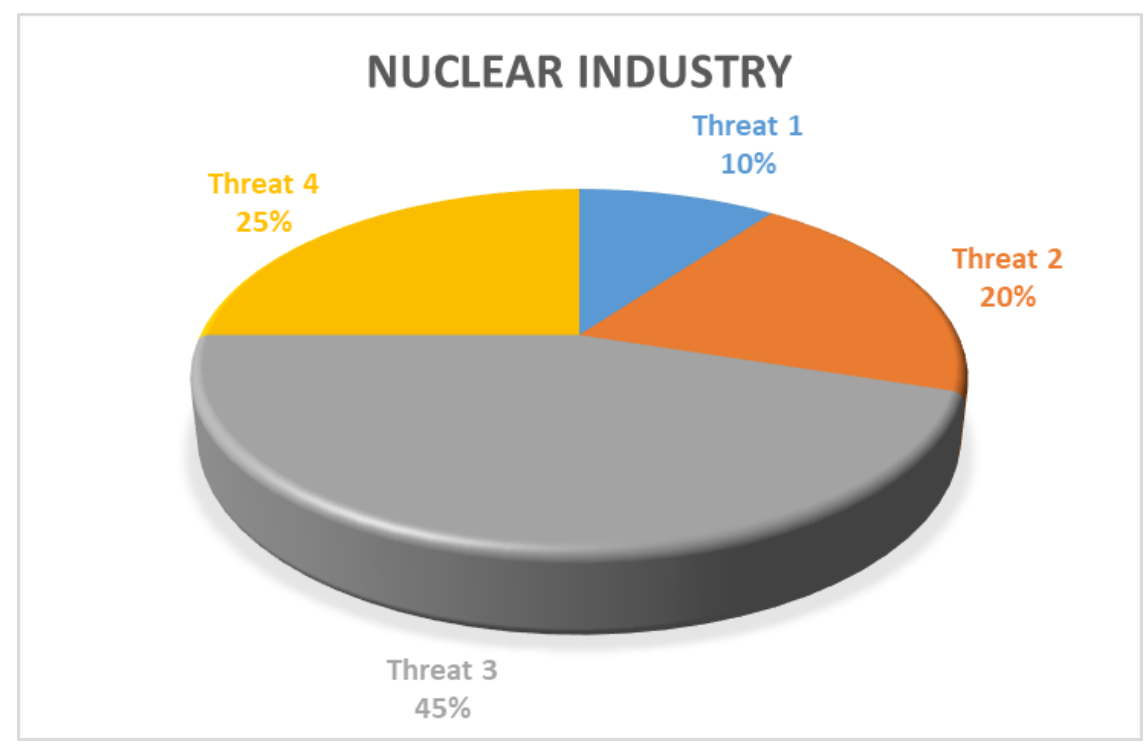

Fig. 4. Percentage of each threat for power and utility industryl

All initiating threats scenario begin to affect the system from the infringed CIA of the system, and the system should have different response strategies for each infringement. The alphabet symbols attached to the end of the scenario name, such as 1C, 1I, or 1A, imply an infringement of confidentiality, integrity, and availability, respectively. As mentioned in section 1.2, the types of infringement should be the criterion for the grouping of the threats, as the mitigation response to each infringement is different. Therefore, the initiating threats $1 \mathrm{C}, 2 \mathrm{C}, 3 \mathrm{C}$, and $4 \mathrm{C}$ are placed in the same group; initiating threats 1I, 2I, 3I, and 4I are in the same group; and initiating threats 1A, 2A, 3A, and 4A are likewise in the same group according to the CIA infringement mitigation strategies. Although different strategies may be used in different systems, grouping is still reasonable because the same strategy will be used for each infringement in the same system. Table 4 shows the results of the initiating threats and their bounding groups for NPPs.

\begin{tabular}{|c|c|}
\hline Bounding Groups & Initiating Threats \\
\hline Confidentiality Infringement & $1 \mathrm{C}, 2 \mathrm{C}, 3 \mathrm{C}, 4 \mathrm{C}$ \\
\hline Integrity Infringement & 1I, 2I, 3I, 4I \\
\hline Availability Infringement & $1 \mathrm{~A}, 2 \mathrm{~A}, 3 \mathrm{~A}, 4 \mathrm{~A}$ \\
\hline
\end{tabular}

Table 4. Initiating threats and their bounding groups 


\section{Conclusion}

In this study, to overcome the limitation that the threat and scenario classifications of existing cyber security assessment methods are generally focused on the engineering evaluation and expert judgement without statistical analysis, initiating cyber threats and their bounding groups were suggested by historical incident analysis. OERs were utilized to conduct threat analyses from the perspective of an attacker for a start of developing a new quantitative cyber security assessment method. Four initiating threats scenarios and three infringements for each initiating threat scenario were identified. Twelve initiating threats were grouped according to the type of infringements. As the analysis focuses on more specific industry, i.e. nuclear power industry, the portions of threats 3 and 4 became higher. The result implies nuclear industry has more frequent occurrence of threat 3 and 4. Also, we can say that the each portion is representing the probability of occurrence of each threat. In other words, to reduce the cyber risk frequency of the nuclear industry, the focus should be on unintentional attacks through portable media and insider attacks by corrupt employees.

This study is powerful in that it presents all the initiating threats and their bounding groups based on actual incidents history. The proposed organization of initiating threats and their bounding groups for NPPs represent a valid first attempt to determine such threats based on actual industrial incidents. This advance can also be further applied to probabilistic safety assessment (PSA), which is the most widely-using risk assessment method, to describe scenarios and models of NPP cyber-risk. Figure 5 shows a hypothetical event tree with 2 barriers of safeguards. By adopting the initiating cyber threats and their bounding groups developed in this study, cyber security can be analysed with logical manner. Further studies will be focused on appropriate quantification of probability of each scenario.

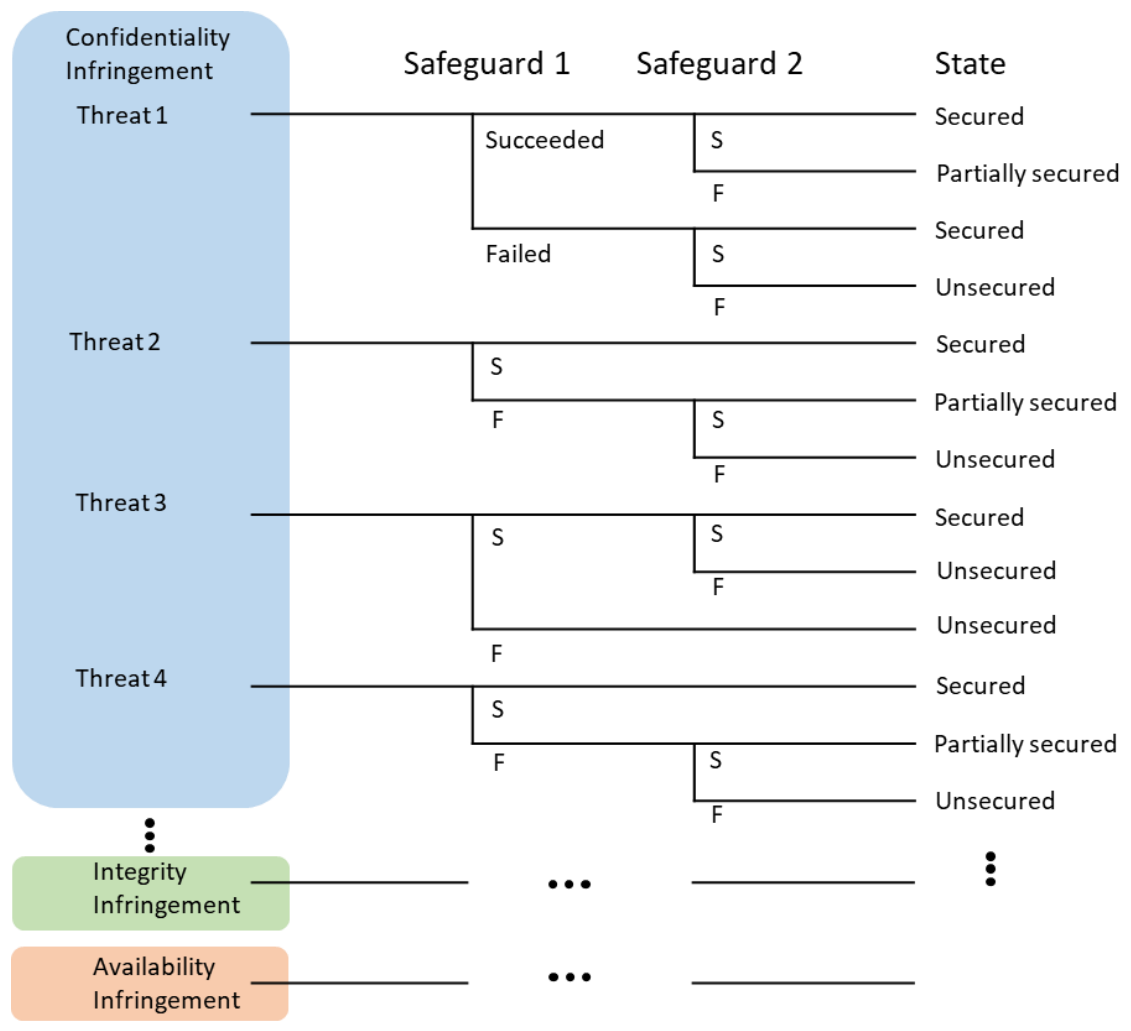

Fig. 5. Suggested initiating threats and its further application to PSA

\section{References}

[1] https://www.nist.gov/cyberframework, (2018). National institute of standard and technology, cyber security framework

[2] Ahn, W. et. al. (2015). Development of Cyber-Attack Scenarios for Nuclear Power Plants Using Scenario Graphs, International Journal of Distributed Sensor Networks, Vol.11

[3] Jajodia, S. \& Noel, S. (2009), Topological Vulnerability Analysis: A Powerful New Approach for Network Attack Prevention, Detection, and Response, Algorithms, Architectures and Information Systems Security, World Scientific, pp.285-305, New Jersey

[4] Kotenko, I. \& Chechulin, A. (2013). A Cyber Attack Modeling and Impact Assessment Framework, Proceeding of the 5th International Conference on Cyber Conflict (CyCon), 2013 5th International Conference on, pp.1-24, Tallinn, Estonia 
[5] Varuttamaseni, A. et al. (2017). Construction of a Cyber Attack Model for Nuclear Power Plants, 10th NPIC-HMIT, Upton, NY

[6] KAFOL, C. \& BREGAR, A. (2017). Cyber Security-Building a sustainable protection, DAAAM INTERNATIONAL SCIENTIFIC BOOK 2017, pp. 081-090

[7] Shostak A. (2014). Threat Modeling, Designing for Security, John Wiley \& Sons

[8] IAEA-TECDOC-719 (1993). Defining Initiating Events for Purposes of Probabilistic Safety Assessment, IAEA, September

[9] http://www.risidata.com/Database, (2015). The repository of industrial security incidents, RISI Online Incident Database.

[10] Neumann, P. (1995). Computer-Related Risks, ACM Press, Addison Wesley

[11] Bartelt, Mark, (1990). Group Questions Software's Reliability after Bruce Accident, Canadian Press

[12] Forester, T. \& Perry M., (2001). Computer Ethics: Cautionary Tales and Ethical Dilemmas in Computing, Massachusetts Institute of Technology

[13] Baylon, C. et al., (2015) Cyber Security at Civil Nuclear Facilities: Understanding the Risks, Chatham House.

[14] http://www.nti.org/gsn/article/russian-warns-of-cyber-terror-against-nuclear-sites, (2006). Nuclear Threat Initiative, Russian warns of cyber terror against nuclear sites.

[15] Pfleeger, C. P. \& Pfleeger S.L., (2012). Analyzing Computer Security: A Threat/Vulnerability/Countermeasure Approach, Prentice Hall.

[16] Kesler, B., (2011). The Vulnerability of Nuclear Facilities to Cyber Attack, Strategic Insights, vol. 10, no. 1, pp. 1525

[17] http://www.nrc.gov/docs/ML0329/ML032970134.pdf. (2003). Markey, E. J., EDO Principal Correspondence Control

[18] U.S. Nuclear Regulatory Commission Office of Nuclear Reactor Regulation, (2007). Effects of Ethernet-based, Nonsafety Related Controls on the Safe and Continued Operation of Nuclear Power Stations,

[19] Zetter, K., (2009). Mossad Hacked Syrian Official's Computer Before Bombing Mysterious Facility, Wired.

[20] Follath, E. \& Holger S., (2009). The Story of 'Operation Orchard': How Israel Destroyed Syria's Al Kibar Nuclear Reactor, Spiegel, 2

[21] Krebs, B., (2008). Cyber Incident Blamed for Nuclear Power Plant Shutdown, The Washington Post.

[22] Poulsen, K., (2009). Ex-Employee Fingered in Texas Power Company Hack, Wired

[23] Symantec Security Response (2013). Stuxnet 0.5: The Missing Link, Symantec

[24] Healey, J., (2013). A Fierce Domain: Conflict in Cyberspace, 1986 to 2012, CCSA Publication.

[25] Albright, D. et al., (2010). Stuxnet Malware and Natanz: Update of ISIS December 22, 2010 Report. Institute for Science and International Security, Washington, D.C.

[26] Zetter, K., (2011). Top Federal Lab Hacked in Spear-Phishing Attack, Wired.

[27] Arène, V., (2011). Le réseau informatique d'Areva piraté, Le Monde Informatique.

[28] Paganini, P., (2014). Malware based attack hit Japanese Monju Nuclear Power Plant, Security Affairs.

[29] Park, J. and Cho, M. South Korea blames North Korea for December hack on nuclear operator,.

[30] Gallagher, S., (2016). German nuclear plant's fuel rod system swarming with old malware, Ars Technica.

[31] Cimpanu, C., (2016). Hackers Steal Research and User Data from Japanese Nuclear Research Lab, Softpedia

[32] Kang, Y.D., (2016) Nuclear I\&C and Huma Factor Engineering from the regulator perspective. Nuclear Safety \& Security Information Conference 2016. DCC, Daejeon, South Korea 